\title{
Práticas Profissionais Interdisciplinares no Contexto das Políticas Públicas na Região dos Campos Gerais, Paraná-Brasil
}

http://dx.doi.org/10.21527/2237-6453.2019.47.324-338

Recebido em: 29/4/2018

Aceito em: 21/12/2018

\section{Danuta Estrufika Cantoia Luiz, ${ }^{1}$ Jussara Ayres Bourguignon²}

\begin{abstract}
RESUMO
A interdisciplinaridade e as redes têm sido objeto de preocupação das políticas públicas no Brasil. Por isso, o Núcleo de Estudos e Pesquisa: Estado, Políticas Públicas e Práticas Sociais - UEPG -, desenvolveu uma pesquisa objetivando analisar práticas profissionais inter e/ou multidisciplinares no contexto das políticas públicas que contribuam com processos emancipatórios. A pesquisa foi realizada por meio de revisão bibliográfica, de entrevistas coletivas com equipes profissionais e de pesquisa documental, coletando dados sobre possíveis práticas multi ou interdisciplinares de caráter emancipatório. A amostra constitui-se em três experiências na Região dos Campos Gerais - Paraná, Brasil -, nas áreas de educação, saúde mental e assistência social. A análise dos dados deu-se mediante pré-análise, exploração do material, tratamento dos resultados e interpretações, sistematizando elementos de práticas multi ou interdisciplinar de caráter emancipatório: compromisso profissional, definição de estratégias para a articulação de objetivos comuns, respeito à diversidade, integração dos debates entre a equipe e população atendida, entre outros.
\end{abstract}

Palavras-chave: Práticas profissionais. Interdisciplinaridade. Multidisciplinaridade. Políticas públicas. Rede.

\section{INTERDISCIPLINARY PROFESSIONAL PRACTICES IN THE CONTEXT OF PUBLIC POLICIES IN THE REGION CAMPOS GERAIS, PARANÁ - BRAZIL}

\begin{abstract}
The interdisciplinary and networks have been the object of concern of public policies in Brazil, for both the Center for Studies and Research: State Public Policy and Social Practices - UEPG -, developed a survey aimed at analyzing professional practices inter and/or multidisciplinary in the context of public policies that contribute to emancipatory processes. The survey was conducted through literature review, press conferences with professional teams and documentary research by collecting data on possible multi - or interdisciplinary practices of emancipatory character. The sample is constituted in three experiences in the Region of Campos Gerais - Parana - Brazil - in the areas of education, mental health and social care: professional commitment, defining strategies for the articulation of common goals, respect for diversity, integration of discussions between staff and population served, among others.
\end{abstract}

Keywords: Professional practices. Interdisciplinaridade. Multidisciplinary. Public policies. Network.

\footnotetext{
${ }^{1}$ Doutora em Serviço Social pela Pontifícia Universidade Católica de São Paulo (2005). Professora do Programa de Pós-Graduação em Ciências Sociais Aplicadas da Universidade Estadual de Ponta Grossa. danutaluiz88@gmail.com

${ }^{2}$ Doutora em Serviço Social pela Pontifícia Universidade Católica de São Paulo. Professora do Programa de Pós-Graduação em Ciências Sociais Aplicadas da Universidade Estadual de Ponta Grossa. juaybo@gmail.com
} 
Considerando que as temáticas interdisciplinaridade e redes têm sido objeto de preocupação das políticas públicas em âmbito nacional, visto sua importância para o avanço de ações voltadas para projetos comprometidos com a perspectiva transformadora, o Núcleo de Estudos e Pesquisa: Estado, Políticas Públicas e Práticas Sociais (Nepps), vinculado ao Programa de Pós Graduação em Ciências Sociais Aplicadas da Universidade Estadual de Ponta Grossa - UEPG - Paraná, Brasil -, desenvolveu uma pesquisa de âmbito regional como uma forma de contribuir para o debate das temáticas em tela.

O presente artigo é fruto de um conjunto de reflexões sistematizadas a partir da experiência dos pesquisadores/autores no Nepps, o qual é constituído de profissionais de diversas áreas, como, por exemplo, direito, psicologia, serviço social, veterinária, educação física, jornalismo, entre outros, mas que (para a realização desta pesquisa de caráter interdisciplinar) possuem um objeto de pesquisa em comum: práticas profissionais de caráter multi ou interdisciplinar no âmbito das políticas públicas na região dos Campos Gerais no Estado do Paraná/Brasil.

A pesquisa partiu da seguinte problematização geral: No âmbito das políticas públicas na região dos Campos Gerais, existem práticas exitosas multi ou interdisciplinares? Em que áreas e locais se encontram tais práticas? Como se configuram em termos de equipe profissional, metodologia de intervenção e resultados alcançados?

Para dar conta de responder a essa problematização da pesquisa, nos propusemos a alcançar os seguintes objetivos: analisar práticas profissionais interdisciplinares no contexto das políticas públicas na região dos Campos Gerais que contribuam com processos emancipatórios, traçar um perfil das práticas identificadas destacando equipe, metodologia de intervenção e resultados alcançados e publicizar as experiências investigadas com os resultados da pesquisa.

A fim de esclarecer qual o entendimento sobre interdisciplinaridade e redes, sistematizamos a revisão de literatura esclarecendo os fundamentos que orientaram a pesquisa no que se refere às categorias interdisciplinaridade, redes e políticas setoriais relacionadas ao tema da pesquisa.

Segundo Thiesen (2008), a interdisciplinaridade visa a superar a visão fragmentada da realidade nos processos de produção e socialização do conhecimento. Propõe, portanto, uma forma inovadora na organização do conhecimento a partir do diálogo entre as diversas áreas das ciências a partir da perspectiva de totalidade. Quanto a esta última categoria, o autor esclarece que, infelizmente, a razão que predominou na base da construção do conhecimento e da interpretação dos fenômenos societários é uma razão baseada na fragmentação do conhecimento sobre o ser humano. Para fazer frente a essa tendência positivista, a interdisciplinaridade caracteriza-se como uma reação, haja vista que procura romper com a fragmentação do conhecimento.

O trabalho interdisciplinar, especificamente no contexto desta pesquisa, envolve a intervenção de profissionais em rede. Por isso, é importante ressaltar que a interdisciplinaridade não ignora as diferenças existentes entre as diversas áreas do conhecimento, no entanto parte do pressuposto de que estas diferenças devem ser compartilhadas ao ponto de buscar construir um objeto de atenção (teórico-prático) comum e capaz de gerar intervenções críticas na realidade (MUNHOZ; OLIVEIRA JUNIOR, 2009). 
Thiesen (2008) enfatiza que somente haverá interdisciplinaridade no trabalho que seja capaz de partilhar o domínio do saber, se tiver a coragem necessária para abandonar o conforto da linguagem estritamente técnica e aventurar-se num domínio que é de todos e de que, portanto, ninguém é proprietário exclusivo. Nesta perspectiva, os profissionais têm um potencial integrador das ações desenvolvidas, na medida em que são responsáveis pelo planejamento, operacionalização, monitoramento e avaliação das práticas desenvolvidas. Ainda, a perspectiva de redes envolve práticas intersetoriais, ou seja, articulação de diferentes políticas em um mesmo contexto ou território de abrangência. Nas experiências analisadas, especialmente na área de saúde e assistência social, a atuação em rede, por parte das equipes interdisciplinares, é essencial para materializar o propósito de cada política pública.

Ante o exposto, ressaltamos a importância de fomentar debates em torno da interdisciplinaridade e de redes, investigando se ambas têm orientado e se têm sido materializadas no contexto municipal, locus onde as equipes profissionais executam as políticas públicas.

O presente artigo está organizado da seguinte forma: num primeiro momento descrevemos o processo metodológico da pesquisa: critérios para definição da amostra e instrumentos de coleta e análise de dados da pesquisa realizada, e, na sequência, apresentamos os principais resultados das experiências selecionadas junto as Políticas Públicas nas áreas de assistência social, educação e saúde na região dos Campos Gerais.

\section{METODOLOGIA DE PESQUISA}

A pesquisa que originou este relato teve caráter qualitativo por não se centrar em expressões numéricas, mas sendo descritiva e se preocupando "com o processo e não simplesmente com resultados e o produto" (SIENA, 2007, p. 62). A pesquisa qualitativa busca uma compreensão particular do que se estuda, não reduzindo os fenômenos a quantidades, números e esquemas generalizados (RAMPAZZO, 2005, p. 60). Em relação a seus objetivos, a pesquisa foi exploratória, pois visa à obtenção de "maior familiaridade com o problema para torná-lo explícito ou a construir hipóteses" (SIENA, 2007, p. 65). Pesquisas exploratórias intencionam proporcionar uma visão geral sobre o assunto abordado, aproximativamente, sobre temas pouco explorados (GIL, 1989, p. 44-45; RAMPAZZO, 2005, p. 54).

O universo escolhido para a pesquisa foi a região dos Campos Gerais/Paraná, nos municípios onde o governo do Estado do Paraná desenvolve políticas públicas por meio das seguintes Secretarias que possuem escritório regional na cidade de Ponta Grossa: Secretaria de Família e Desenvolvimento Social, Secretaria de Educação, Secretaria de Saúde e Secretaria do Trabalho, Emprego e Economia Solidária, no ano de 2013.

A investigação ocorreu em 20 cidades: Arapoti, Carambeí, Castro, Curiúva, Imbaú, Imbituva, Ipiranga, Ivaí, Jaguariaíva, Ortigueira, Palmeira, Piraí do Sul, Ponta Grossa, Porto Amazonas, Reserva, São João do Triunfo, Sengés, Telêmaco Borba, Tibagi e Ventania.

Para definição dos sujeitos de pesquisa foi adotado o seguinte procedimento:

Contato com as chefias/técnicos dos escritórios regionais das secretarias de Estado (Saúde, Educação e Assistência Social) para a identificação das experiências exitosas nos municípios selecionados para a pesquisa. Nesta fase da pesquisa ficaram 
selecionadas as experiências das políticas públicas: na área da Saúde o município de Palmeira com o Programa de Saúde Mental; na área de Educação os municípios de Ponta Grossa e Imbituva com projetos multidisciplinares para Educação das Relações Étnico-Raciais e para o Ensino de História e Cultura Afro-Brasileira e Africana e na área de Assistência Social os municípios de Castro, Palmeira e Ponta Grossa, com as práticas desenvolvidas pelas equipes técnicas junto aos Centros de Referência em Assistência Social, equipamento de proteção básica da Política Nacional de Assistência Social.

Contato com as equipes selecionadas para esclarecimento dos objetivos da pesquisa, solicitação de documentos sistematizados sobre a experiência e agendamento das entrevistas. Nesta fase o grupo de pesquisadores do Nepps se subdividiu em grupos de dois a quatro integrantes (seguindo o critério de proximidade com a área pesquisada) para a coleta de dados nos diferentes municípios da região.

Como procedimentos metodológicos, a pesquisa foi desenvolvida por meio de pesquisa bibliográfica, pesquisa documental, entrevista individual e/ou coletiva (conforme a disponibilidade de cada equipe de profissionais), análise de conteúdo no formato temático-categorial e, como forma de socializar os resultados da pesquisa com todas as equipes participantes, o Núcleo de Pesquisa organizou e realizou o Seminário de relatos das experiências e das práticas interdisciplinares selecionadas (este momento da pesquisa está descrito ao final do artigo).

A realização das entrevistas com os profissionais (com nível superior) que compõem as equipes dos programas/projetos suprarreferidos ocorreram em conformidade com os cuidados éticos em pesquisa, e todos os participantes assinaram individualmente o Termo de Consentimento Livre e Esclarecido (TCLE). A pesquisa utilizou um roteiro de entrevista semiestruturada, com questões abertas e fechadas (as quais foram gravadas e transcritas), delimitadas nos seguintes aspectos: caracterização da equipe, constituição da equipe multi ou interprofissional, público-alvo, objetivos do trabalho/projeto/ experiência, referencial balizador da experiência, desenvolvimento da experiência, especificidades da atuação da equipe, aspectos comuns nas práticas desenvolvidas, dificuldades e facilidades enfrentadas para a realização do trabalho multi ou interdisciplinar, construção de espaços para o exercício multi/interdisciplinar, resultados concretos alcançados junto aos grupos trabalhados.

Neste artigo os resultados serão demonstrados mediante síntese de cada experiência pesquisada, observando suas principais marcas quanto ao trabalho multi ou interdisciplinar no âmbito das políticas analisadas.

\section{PRINCIPAIS RESULTADOS DA PESQUISA E EXPERIÊNCIAS ANALISADAS}

\section{O Programa de Saúde Mental do Município de Palmeira - PR}

O município de Palmeira apresenta, segundo o IBGE (BRASIL, 2013), uma estimativa de população de 33.469 com uma densidade demográfica de 22 habitantes por $\mathrm{Km}^{2}$. O município apresenta $50 \%$ de cobertura de sua população pela estratégia Saúde da Família, possui 2 hospitais gerais, 5 unidades de saúde da família, 11 unidades básicas de saúde rurais (com um auxiliar de enfermagem e um agente comunitário de saúde (ACS) permanentes e uma equipe médica e de enfermagem itinerante) e conta ainda com 
duas Unidades Básicas de Saúde Urbana. Palmeira conta também com o atendimento especializado ofertado pelo Consórcio Intermunicipal dos Campos Gerais e governo do Estado do Paraná ${ }^{3}$.

As ações de saúde mental já eram realizadas no município, mas de forma isolada, não sistematizadas, gerando uma prestação de serviços fragmentada (MARTINS et al., 1998). Diante desse quadro, os profissionais começaram a se reunir para discutir a necessidade de o município dispor de um Programa Municipal de Saúde Mental (PMSM). O que aconteceu em agosto de 1998, passando a ser referência para as ações de saúde mental do município. Atualmente, o programa está subdividido em: 1) Equipe Clínica, específica de assistência ambulatorial às pessoas em sofrimento psíquico; 2) Equipe Ampliada, com foco na atenção primária, sendo referência para a atuação na rede do SUS; 3 ) Rede Caracas, rede municipal de saúde mental, articulada com outros setores do serviço público e de organizações da sociedade civil.

Cada profissional da saúde envolvido no Programa possui especificidades inerentes à sua profissão. Em um contexto geral, no entanto, é possível denotar que existem práticas compartilhadas pelo grupo. Estas características apontam uma convergência de discurso dos membros que trabalham em prol de objetivos comuns, ainda que voltadas cada qual a sua área específica. Como grupo construído com vistas à interdisciplinaridade, é válido ressaltar que a interdisciplinaridade não ignora as diferenças existentes entre as diversas áreas do conhecimento, entretanto parte do pressuposto de que estas diferenças devem ser compartilhadas a ponto de buscar construir um objeto de atenção (teórico-prático) comum e capaz de gerar intervenções críticas na realidade (MUNHOZ; OLIVEIRA JUNIOR, 2009).

Quanto às práticas comuns a todos, destaca-se o acolhimento. Todos os profissionais ouvidos citam em seus discursos o acolhimento da pessoa que chega, que é a ocasião primeira quando se escuta este indivíduo, e é feita a triagem e o encaminhamento do mesmo. Cada profissional atua em um momento, ainda que nesta mesma etapa de "acolher".

Também, os profissionais reconhecem em suas falas como o trabalho em conjunto é agregador, complementar e interligado, indo ao encontro do escopo do Projeto que prevê interdisciplinaridade. Como Thiesen (2008) ressalta, a interdisciplinaridade trata-se de um movimento que acredita na criatividade das pessoas, na complementaridade dos processos, na inteireza das relações, no diálogo, na problematização, na atitude crítica e reflexiva. Enfim, numa visão articuladora que rompe com o pensamento disciplinar, parcelado, hierárquico, fragmentado, dicotomizado e dogmatizado que marcou, por muito tempo, a concepção cartesiana de mundo, e que logo, deste modo, se apresenta na experiência do grupo de trabalho ao reconhecer a conexão e complementaridade de cada etapa - do acolhimento às visitas domiciliares.

\footnotetext{
3 O Consórcio Intermunicipal de Saúde dos Campos Gerais (Cimsaude) tem por objetivo contratar serviços complementares, como consultas especializadas (cardiologia, dermatologia, oftalmologia, entre outras) e exames especializados (ultrasom, mamografia, Dopler, eco-cardiograma...) relativos à atenção especializada para dar suporte a todos os municípios da 3a Regional de Saúde Disponível em: http://www.cimsaude.org/cimsaude.
} 
Pensando em práticas específicas, os agentes comunitários de saúde estabelecem elos de ligação entre as demandas da comunidade e o serviço de saúde, aproximando o paciente aos demais profissionais, na medida em que vão até as casas dos pacientes, conhecendo mais de perto suas realidades e famílias, construindo "elos" que solidificam a relação e a compreensão de suas necessidades. Estes profissionais fazem a busca ativa ${ }^{4}$ do paciente e reconhecem os problemas diretamente nas comunidades, ao longo de visitas periódicas.

Já os Psicólogos elencam, ao menos, seis funções específicas compartilhadas entre os três psicólogos entrevistados. São elas: avaliação psicológica, psicoterapia, oficina terapêutica, apoio psicológico e terapia focal. Ressalta-se que as dinâmicas também são realizadas por outros profissionais, porém a partir da práxis do mesmo.

A outra categoria de profissionais envolvidos com o Projeto de Saúde Mental em Palmeira é o assistente social, que participa essencialmente do acolhimento e da triagem e no acolhimento. Neste processo de trabalho a escuta se faz essencial enquanto instrumental que potencializa a garantia de acesso às demais políticas públicas, por meio de encaminhamentos e orientações. Comum nos depoimentos dos profissionais é a necessidade de abordar o usuário dos serviços de saúde mental no contexto em que ele se insere. Ou, dito nas palavras de Yazbek (2004, p. 45), “[...] se for desconsiderada a totalidade (...) a desconexão do micro-social, do particular para com o todo [...]" se perde a visão de totalidade da questão trabalhada. Ou seja, a interdisciplinaridade é diretamente relacionada à perspectiva de totalidade: a relação das partes com o todo é um conjunto articulado e interconectado numa mútua relação. "Depois de os ter estudado a cada um em particular, é necessário examinar a sua relação recíproca" (MARX, 1983, p. 225), integrando seus elementos ao conjunto e as partes ao todo, "[...] se bem que nunca se possa chegar a uma totalidade que não seja, ela mesma, elemento ou parte [...]" (GOLDMANN, 1979, p. 13).

Não se deve ignorar, a priori, que as diferentes profissões e funções desenvolvidas pelos agentes têm uma história, formação e cultura próprias, que certamente influenciam no trabalho tomado isoladamente, assim como dentro da perspectiva de grupo e até na interdisciplinaridade.

Nessa busca de superação do trabalho isolado e específico, concebendo-o num contexto global da sociedade e da necessidade dos sujeitos envolvidos, a equipe do Programa de Saúde Mental tem buscado práticas capazes de engendrar a melhoria e eficiência do trabalho. Para tanto, o grupo se reúne frequentemente para discussão de casos, avaliação do Programa, elaboração de atividades, estudos e atualizações na área, bem como participando e promovendo eventos relacionados ao tema; isso tudo na perspectiva do melhor diagnóstico e consolidação do trabalho e como mecanismo de fortalecimento da equipe. Tal conjugação de esforços, que supera a mera convivência entre saberes diferentes (multidisciplinaridade), tem se demonstrado como um elemento fundamental para a eficiência do trabalho e a melhor aceitação junto a comunidade atendida, conforme corroborado por falas recorrentes dos membros da equipe.

\footnotetext{
${ }^{4}$ Por busca ativa entende-se estratégia adotada do Plano Brasil Sem Miséria que significa levar o Estado ao cidadão. Esta busca coloca o Estado até os que precisam, sem esperar que os pobres procurem o poder público (BRASIL, 2014a).
} 
Por mais que se reconheçam algumas dificuldades na metodologia de trabalho adotada pelo Programa de Saúde Mental, como carências estruturais, dificuldade de compreensão acerca da perspectiva de trabalho por parte de alguns profissionais do atendimento de saúde (por exemplo: aproximação dos médicos do atendimento geral com os psiquiatras e médicos do Programa), são inequívocos os avanços e benefícios da prática interdisciplinar aplicada, o que se percebe pela análise das falas dos sujeitos envolvidos.

Na coleta de dados percebeu-se a importância de práticas educativas e democráticas que sejam capazes de socializar e universalizar o conhecimento/saber, fato que contribui para a elaboração de uma cultura política mais madura das classes subalternas. Essa ação favorece rupturas no senso comum com relação à Saúde Mental, de que as práticas de mobilização junto a comunidade, às escolas e creches do município, desenvolvidas pela equipe profissional, podem contribuir.

Outro elemento apontado como resultante do trabalho interdisciplinar desenvolvido refere-se à diminuição dos internamentos, reduzido número de suicídios e monitoramento de casos relacionados e valorização/responsabilização da família sobre a saúde do doente. Quanto à diminuição dos internamentos, há que se destacar a direção do trabalho assumida pela equipe no sentido de priorizar o tratamento do paciente da Saúde Mental inserido no âmbito familiar e social, sendo o internamento uma medida de última instância, usado para casos mais graves.

Nota-se uma noção de proteção social que supera a unilateralidade de responsabilização no cuidado do paciente da saúde mental - a união de forças de todas as esferas: Família, Estado e Sociedade, elemento que se nota em relação ao incentivo do protagonismo da família e do paciente no processo do tratamento.

A legitimidade do trabalho de forma geral, que se mostra no respeito da população e do poder público quanto à conduta do serviço (não internamento - quando "forças externas" faziam pressão para tanto), também é elencada como um resultado positivo. O respeito ao conhecimento técnico e à autonomia da equipe profissional é um elemento bastante significativo enquanto resultado de um trabalho interdisciplinar. Ainda no âmbito da relação com o poder público e a população, a equipe visualiza o desenvolvimento de ações estratégicas como um meio de otimizar o serviço, por exemplo o uso da "carteirinha", instrumento de referência e contrarreferência, que possibilita acompanhar todas as ações realizadas pela equipe e pelos serviços em torno das demandas do usuário. Somado a isto, os relatos apontam para outro resultado, que é a maturidade do grupo, na medida em que a comunicação entre os profissionais da equipe e as decisões tomadas coletivamente possibilitam resolutividade às ações no âmbito da saúde mental no município (LUIZ et al., 2014).

\section{As Equipes Multidisciplinares e a Educação das relações étnico-raciais e para o ensino de História e Culturas Afro-Brasileira e Africana}

Este tópico do artigo aborda as experiências exitosas e com marca multidisciplinar desenvolvidas em três escolas estaduais na região de abrangência do Núcleo Regional de Educação situado em Ponta Grossa/PR, cuja ênfase é voltada para ações em torno das relações étnico-raciais e para o ensino da História e Culturas Afro-Brasileira e Africana. 
A temática africana e afro-brasileira remete a uma pauta política e social relevante no âmbito da escola e em sua prática pedagógica e de formação do cidadão brasileiro. Assim, na área da educação brasileira, as ações e medidas afirmativas visam a desconstruir perspectivas conservadoras e construir práticas de igualdade racial. 0 marco inicial é a lei no 10.639/03, que altera os artigos 26-A e 79-B da Lei de Diretrizes e Bases da Educação Nacional - LDB -, lei no 9394/96, definindo a obrigatoriedade do ensino de História e Culturas Africana e Afro-Brasileira na educação básica. Essa legislação aponta a necessidade da promoção e reeducação das relações étnico-raciais e do combate às ideias e às práticas racistas que ainda persistem no imaginário e nas relações sociais vivenciadas por educadores, comunidade, familiares e educandos.

O parecer 003/2004 do Conselho Nacional de Educação instituiu as Diretrizes Curriculares Nacionais para a Educação das Relações Étnico-Raciais e para o Ensino de História e Culturas Afro-Brasileira e Africana. No caso do Estado do Paraná, foi pela deliberação 04/2006 do Conselho Estadual de Educação (CEE) que se estabeleceu normas complementares para as Diretrizes. A Secretaria de Estado de Educação - Seed -, por meio da Superintendência da Educação - Sued -, lançou a instrução no 017/2006, que tem como objetivo a efetivação da deliberação 04/2006 do CEE, com a criação de equipes multidisciplinares.

Com relação à competência da equipe multidisciplinar das escolas da educação básica, a instrução orienta que estes devem elaborar e aplicar um plano de ação, com conteúdos e metodologias de atividades relacionadas à questão racial, sendo incorporado no projeto político-pedagógico bem como legitimado pelo regimento escolar. É realizada também pela equipe a formação permanente com os demais profissionais da educação, bem como da comunidade escolar, e visa a subsidiar o conselho escolar objetivando a ação de enfrentamento ao preconceito, racismo e discriminação dentro do ambiente escolar, apoiando, assim, os professores, equipe pedagógica, direção, funcionários, pais, mães, alunos (PARANÁ, 2010a).

O trabalho deve ser organizado nas modalidades de encontros e seminários; a carga horária que a escola tem de cumprir deve estar em consonância com o cronograma de execução, sendo sugerido pela própria equipe e aprovado por esta no início do ano letivo. Embora a composição das equipes se encaixe no descrito como equipes multidisciplinares, a proposta de efetivação do trabalho na escola busca superar os problemas de desigualdades e descriminações, procurando o reconhecimento e "valorização das raízes africanas da nação brasileira, ao lado das indígenas, européias e asiáticas" - CEE parecer 04/2006 § 2ㅇ (PARANÁ, 2006a).

A instrução no 017/2006 preconiza que as ações aconteçam durante o decorrer do ano letivo, tendo como ponto de culminância o dia 20 de novembro - dia da consciência negra, de forma articulada ao projeto político pedagógico da escola e envolvendo a comunidade escolar bem como representantes da sociedade que atuam com esta temática.

Os projetos das equipes multidisciplinares nas escolas garantem ações efetivas e dão vida à lei no 10.639/03, passando a ter a obrigatoriedade do ensino de História e Culturas Africana e Afro-Brasileira na educação básica. Essa legislação aponta a necessidade da promoção da reeducação das relações étnico-raciais no combate a ideias e práticas racistas que ainda persistem no imaginário e nas relações sociais. 
Participaram da pesquisa três escolas da Rede estadual de ensino nos municípios de Ponta Grossa e Imbituva. As equipes são compostas por pedagoga, agente educacional, representante de instâncias colegiadas, professores das áreas de humanas, de biológicas e de exatas. Os profissionais entrevistados foram os coordenadores pedagógicos e diretores das escolas.

O foco de atenção da escola, por intermédio das equipes multidisciplinares é "[...] o combate a qualquer tipo de preconceito e na conscientização da comunidade escolar sobre o respeito que deve ser dispensado a todas as culturas existentes com as quais nos deparamos no dia a dia" (IMBITUVA, [201-?]). Os temas abordados tratam das culturas africana e afro-brasileira, da cultura indígena e da diversidade de gênero.

O público-alvo das equipes multidisciplinares são os professores e funcionários e os alunos do estabelecimento de ensino, instituindo o processo de formação continuada por meio da temática da História e Culturas Africana e Afro-brasileira. Em especial os professores e funcionários participam por meio de formação continuada. Neste contexto, a "formação continuada pode possibilitar a reflexividade e a mudança nas práticas docentes, ajudando os professores a tomarem consciência das suas dificuldades, compreendendo-as e elaborando formas de enfrentá-las" (LIBÂNEO, 2008, p. 228).

Posteriormente, seguiram os questionamentos em relação às metodologias, formas de trabalho e estratégias utilizadas pelas equipes. A instrução 010/2010 estabeleceu as competências das equipes multidisciplinares, orientando as formas para se trabalhar e a responsabilidade da Seed e das equipes/escolas.

A pesquisa verificou que as propostas de organização do trabalho das equipes partem das instâncias administrativas superiores da Seed/PR e a sua operacionalização é complementada com as proposições específicas de cada escola. Essa forma de organização, porém, não é fixa, e cada unidade educacional pode adaptar-se conforme a sua realidade. Um ponto preocupante foi o relato da dificuldade de reunir toda a equipe. Isso se deve ao fato de que o professor que trabalha na rede estadual de ensino normalmente divide a sua carga horária de trabalho entre os períodos matutino, vespertino e noturno, em diferentes escolas, para completar seu regime de trabalho, conforme a escala de aula disponível. Assim, o professor é obrigado diariamente a realizar diversos deslocamentos entre escolas e turno. Isto, acontecendo com 20 professores ao mesmo tempo, gera dificuldades de agendamento de reuniões para a equipe multidisciplinar, afetando o planejamento das suas ações. Os seminários e cursos organizados em torno dos projetos, no entanto, possibilitam não somente o encontro dos professores e a interação das equipes, mas o planejamento das ações.

O enraizamento do preconceito e a dificuldade de sua superação entre os professores também pode ser evidenciada. Conforme Arantes e Silva (2009), uma lei não implica necessariamente uma mudança de práticas historicamente constituídas de desvalorização da história e da cultura do povo negro nas salas de aula; e, mesmo no caso de se inserir a temática, sabemos que o enfoque dado pelos professores pode até reforçar ainda mais a situação de exclusão do povo negro do sistema oficial de ensino. Da Matta (1986, p. 27) deixa claro que, "numa sociedade onde não há igualdade entre as pessoas, o preconceito velado é forma muito mais eficiente de discriminar pessoas de cor, desde que elas fiquem no seu lugar e 'saibam' qual é ele". 
Para Silva e Barbosa (2012), apesar das conquistas legais ocorridas nos últimos anos, garantindo a singularidade, bem como a pluralidade no ambiente escolar, a população negra ainda recebe uma escolarização fundamentada no desejo de branqueamento do Brasil, ou seja, ainda é uma escola que nega a existência do negro no sistema educacional.

As equipes multidisciplinares, porém, por intermédio dos trabalhos e pesquisas continuados, estão conseguindo avançar na medida em que pautam a temática na prática cotidiana de formação dos alunos e dos próprios professores, sustentando uma nova possibilidade de construção de relações mais democráticas dentro e fora da escola.

A metodologia pode ser compreendida como um posicionamento ético-político do professor ante as demandas de seu trabalho. Ou seja, uma prática pedagógica que demanda uma intencionalidade para além dos resultados imediatos. Assim, as metodologias utilizadas pelos professores devem estar relacionadas com a concepção pedagógica, com a visão de educação, de homem e de sociedade das escolas de atuação, construída criticamente a partir da reflexão que fazem sobre o trabalho que realizam e expressam nos seus projetos político-pedagógicos. Reconhece-se, no entanto, o esforço das equipes em garantir um conjunto de ações e procedimentos pautados em recursos didáticos para assegurar o envolvimento de alunos e professores em torno da temática étnico-racial e da cultura africana.

Traços como estes apontam para este projeto como uma atividade exitosa no interior da escola também no sentido de superar entraves, como a individualização do trabalho coletivo e a fragmentação do processo de educação.

Outro ponto fundamental, apontado pelas entrevistadas, é que o processo de formação dos professores, preconizado pelo projeto, oportuniza romper com a falta de compreensão da realidade social em que o professor está inserido e superar a visão de mundo limitada que impede o entendimento das novas dinâmicas familiares dos alunos que fazem parte da escola. Especificamente quanto à abordagem da cultura afrodescendente, oportuniza-se percebê-la como temática essencial a ser trabalhada no currículo escolar, contribuindo para o reconhecimento da identidade do negro e da sua relação com a sociedade na busca de construção de relações sociais democráticas e emancipatórias.

É possível articular os relatos com o que é exposto na instrução 010/2010, mostrando que, com a execução das atividades referentes à temática da cultura africana e da questão racial, os professores buscam refletir, enriquecer o trabalho e superar o preconceito. Assim, resultados positivos são narrados, como o progresso na adesão ao trabalho da equipe, a importância da formação continuada, a utilização de novos recursos pedagógicos e a diminuição de ocorrências ligadas a preconceito racial (BOURGUIGNON et al., 2014).

\section{Centros de Referência de Assistência Social (Cras): possibilidades de práticas interdisciplinares e emancipatórias}

A investigação sobre as práticas de caráter emancipatório realizadas no âmbito da Política Nacional de Assistência Social por meio dos Cras, equipamento social que faz parte da rede de serviços socioassistenciais de um município, ocorreu junto aos três estabelecimentos dos seguintes municípios: Castro, Palmeira e Ponta Grossa. 
No contexto brasileiro, as ações de assistência social estão organizadas, dentro do Sistema Único de Assistência Social (Suas), em dois tipos de proteção social: Proteção Social Básica e Proteção Social Especial.

A Proteção Social Básica, foco desta pesquisa, destina-se à prevenção de riscos sociais e pessoais pelo desenvolvimento de programas, projetos, serviços e benefícios a indivíduos e famílias em situação de vulnerabilidade social e atua por meio de diferentes unidades, dentre as quais destacam-se os Centros de Referência de Assistência Social (Cras) (BRASIL, 2009, p. 9).

O Cras se configura como uma unidade pública estatal descentralizada da política de assistência social, e se localiza em áreas de vulnerabilidade social. É um espaço considerado como a porta de entrada para o Suas, que visa a prevenir a ocorrência de situações de riscos sociais e vulnerabilidades nos territórios, possibilitando às famílias o acesso à rede de proteção social e assistência social (BRASIL, 2009, p. 9).

De acordo com o caderno de Orientações Técnicas, o Cras cumpre seus objetivos com ações que possibilitem o desenvolvimento de potencialidades pessoais, o fortalecimento de vínculos familiares e comunitários, bem como a garantia de acesso aos direitos sociais (BRASIL, 2009).

O principal serviço oferecido pelo Cras é o trabalho social com famílias do Programa de Atenção Integral à Família (Paif), que visa a fortalecer as suas funções protetivas, prevenindo o rompimento de vínculos. Ainda, o Cras exerce a função de gestão territorial da rede socioassistencial de proteção social básica, trabalhando, de forma articulada, com a rede local (BRASIL, 2009, p. 9).

As unidades do Cras podem ofertar diretamente à população os serviços socioassistenciais da proteção básica, de caráter preventivo, protetivo e proativo, como os serviços de convivência e fortalecimento de vínculos para crianças, idosos, adolescente, programa pró-jovem adolescente, projetos de inclusão produtiva, entre outros, de acordo com sua disponibilidade de recursos físicos e equipe técnica compatível com o serviço. Na falta destes recursos, os serviços podem ser oferecidos por outra unidade pública ou entidades de assistência social privada, sem fins lucrativos, referenciadas ao Cras (BRASIL, 2009).

Cabe destacar que os serviços ofertados nas unidades do Cras devem responder às necessidades e potencialidades das famílias do território no qual ele está inserido, e devem ser planejados a partir de diagnóstico socioeconômico da realidade e demandas das famílias e das situações de risco e/ou vulnerabilidades já conhecidas na sua área de abrangência.

Toda unidade do Cras conta com uma equipe de referência, constituída por profissionais responsáveis pela gestão territorial da proteção básica, organização dos serviços ofertados no Cras e pela oferta do Paif. A equipe mínima necessária depende do número de famílias referenciadas. Cras com até 2.500 famílias referenciadas devem contar com dois técnicos de nível médio e dois técnicos de nível superior, sendo um profissional de Serviço Social e outro de Psicologia (BRASIL, 2009). Desta pesquisa participaram, respondendo ao roteiro de entrevista, profissionais de Psicologia e Serviço Social. 
As equipes de referência dos Cras são interdisciplinares e os perfis dos profissionais devem favorecer o desenvolvimento das funções da unidade. No âmbito do Suas, o trabalho interdisciplinar é adotado como processo de trabalho, pois compreende-se que as situações de risco e vulnerabilidade social, como objeto da ação, são fatos complexos e multifacetados, exigindo respostas diversas, fruto de construções coletivas entre técnicos com diferentes formações.

Os resultados alcançados com a pesquisa apontam aspectos referentes aos desafios da atuação interdisciplinar e seus avanços, e aspectos que tratam dos resultados concretos alcançados junto aos usuários.

O olhar interdisciplinar favorece a apreensão crítica dos múltiplos determinantes que compõem as expressões da questão social, sejam elas situações de violência, pobreza, abandono, entre outras. Tal perspectiva é, inclusive, parte das orientações da Política Nacional de Assistência Social. De acordo com os depoimentos, os avanços estão no processo de institucionalização do trabalho interdisciplinar no âmbito dos Cras, como na realização de reuniões periódicas entre os profissionais, por exemplo. No que se refere aos resultados alcançados no âmbito da intervenção junto dos usuários, os técnicos ponderam que parte dos limites ainda residem na expectativa de que a Política em pauta está voltada estritamente para demandas emergenciais, no entanto tais resultados também são visualizados em termos processuais, tanto no que se refere à autonomia material (financeira) quanto ao despertar de uma visão crítica, de um resgate de sujeito de sua própria história.

Com isso, podemos aferir que as práticas profissionais realizadas no âmbito dos Cras avançam no sentido de superar as ações meramente emergenciais de atendimento de carências econômicas, que servem de instrumentos para a manutenção do sistema e do apaziguamento do conflito de classes. Conforme pondera a PNAS (BRASIL, 2005), produto da pactuação do diálogo entre Estado e sociedade civil, a Assistência Social deve fomentar uma visão social capaz de entender que a população tem necessidades, mas também tem possibilidades e capacidades que podem ser desenvolvidas. Desta forma, uma análise de situação não deve ser feita somente a partir de "ausências", mas também de "presenças", de desejos em superar a situação atual.

Nesta perspectiva, o Suas insere um conjunto de novos pressupostos tão caros à área, ganhando destaque o da universalidade, superando a focalização; a centralidade da prevenção, em detrimento das ações emergenciais; perfil claro e coerente da rede de atendimento, superando a confusão que, historicamente, tem envolvido o embricamento com as áreas da saúde e da educação, somada às ações de caridade desenvolvidas por entidades tradicionais; o fortalecimento das instâncias de controle social, com ênfase na participação dos usuários; a visibilidade das fontes de financiamento, com alocação nos fundos orçamentários e responsabilidades definidas a cada ente federado; e a construção de um sistema de monitoramento e avaliação da política, que visa a superar o pragmatismo da área, que, historicamente, atendia demandas segmentadas sem prévio diagnóstico e planejamento (BRASIL, 2005, 2009).

Tal ruptura, sem dúvida, tem impactado na qualidade dos serviços prestados, como podemos ponderar a partir dos depoimentos dos técnicos entrevistados. Os avanços foram apontados como processos que se apresentam no protagonismo de alguns sujeitos e/ou famílias na medida em que buscam, pautados nos serviços socioassisten- 
ciais, superar as condições de vulnerabilidade social em que se encontram. Especificamente, verifica-se os avanços dos usuários com relação à busca por escolaridade, emprego, qualificação profissional; ou mesmo na participação e vinculação aos serviços, quando demonstram o desejo de saber, aprender, conhecer e trocar experiências que são muito relevantes, pois favorecem a autoestima e o desenvolvimento pessoal e social (SOUZA et al., 2014).

\section{CONCLUSÕES}

A pesquisa realizada pela equipe do Nepps (BOURGUIGNON et al., 2014; LUIZ et al., 2014; SOUZA et al., 2014) mostra que refletir sobre experiências exitosas que tenham caráter multi ou interdisciplinar é tarefa difícil, considerando que as práticas observadas nesta pesquisa, em torno destas perspectivas, estão acontecendo e ainda enfrentando muitos desafios para alcance dos seus objetivos. É muito importante destacar, no entanto, que as experiências foram consideradas exitosas, justamente porque estão buscando alternativas de materializar propostas que contribuam para a emancipação social. Estas experiências contribuem direta e indiretamente na consolidação de uma nova cultura, baseada em valores democráticos, dentro da escola, das unidades de saúde mental e no âmbito da assistência social.

Cabe destacar, quanto às experiências de natureza multidisciplinar, que este é um primeiro passo para exercitar a construção e a partilha de saberes em torno de um objeto comum. À medida que ocorram investimentos continuados na formação dos profissionais, com desdobramentos em práticas concretas partilhadas com todos os sujeitos envolvidos, visualiza-se a possibilidade de avançar para a construção de experiências interdisciplinares. Trata-se de um potencial embrião para o exercício de práticas e pesquisas com caráter interdisciplinar.

É importante ressaltar que a interdisciplinaridade, enquanto experiência que se manifesta na realidade social de exercício profissional, não é uma fórmula que se aplica, e seus resultados podem ser mensurados quantitativamente. O que se buscou neste estudo foi analisar qualitativamente momentos de um processo em desenvolvimento de uma experiência de trabalho interdisciplinar bem-sucedida.

Esta interdisciplinaridade pode ser percebida como mostrado ao longo do estudo, quando integrantes relatam como cada elemento, em suas especificidades, complementa o todo do trabalho em prol de potencialização do conhecimento, característica que permeia o debate dos diferentes profissionais envolvidos.

Pautado em uma concepção de práxis em que a articulação entre teoria e prática movimenta as ações profissionais, neste estudo o entendimento é de que as práticas profissionais contribuem para a transformação e exercício da cidadania relativos a todos os sujeitos envolvidos: pacientes, familiares, profissionais, escola, alunos, usuários das políticas públicas e comunidade.

Os relatos acerca dos resultados demonstram um processo de "rupturas moleculares", expressão fundamentada em Luiz (2011), que permite interpretar ações cotidianas (como as relatadas neste artigo, advindas da práxis profissional num contexto de trabalho interdisciplinar) como parte de um processo (de longo prazo) de mudanças sociais. 
Essas mudanças envolvem questões culturais, de elevação do senso comum ao bom senso. Essas "rupturas moleculares" referem-se a ações concretas, que, embora não rompam de imediato com a estrutura social mais ampla, fazem parte de processos que influenciam novos modos de pensar e de atuar na coletividade (LUIZ, 2011).

As reflexões empreendidas neste artigo sobre práticas interdisciplinares constituem-se em oportunidade de debate sobre a necessidade de os profissionais atuantes em políticas públicas avançarem no exercício de práticas fortalecidas pelo compartilhamento de objetivos, referências teóricas e ações, tendo em vista a interdisciplinaridade.

\section{REFERÊNCIAS}

ARANTES, A. S.; SILVA, F. C. "História e cultura africana e afro-brasileira: repercussão da Lei 10.639 nas escolas municipais da cidade de Petrolina-PE." In: SILVA, M. A. et al. (org.). Educação e diversidade: estudos e pesquisas. Recife: Gráfica J. Luiz Vanconcelos Ed., 2009. Disponível em: http://www.ufpe.br/cead/ estudosepesquisa/textos/artigos_vol_1.pdf. Acesso em: 10 fev. 2014.

BOURGUIGNON, Jussara Ayres et al. "As equipes multidisciplinares: reflexões sobre uma experiência exitosa em educação." Relatório de Pesquisa do Núcleo de Estudos em Estado, Políticas Públicas e Práticas Sociais. Ponta Grossa: UEPG, 2014.

BRASIL. Diretrizes curriculares para a educação das relações étnico-raciais e para o ensino de história e cultura afro-brasileira e africana. Brasília, DF, out. 2004.

BRASIL. Portal Brasil. Plano Brasil sem miséria. 2014a. Disponível em: http://www.brasilsemmiseria.gov. br/busca-ativa. Acesso em: 5 set. 2014.

BRASIL. Ministério do Planejamento, Orçamento e Gestão. Instituto Brasileiro de Geografia e Estatística. IBGE Cidades. 2013. Disponível em: http://www.cidades.ibge.gov.br/xtras/home.php. Acesso em: 12 out. 2013.

BRASIL. Ministério da Educação e Cultura. Lei no 10.639 de 9 de janeiro de 2003. Brasília: MEC, 2003.

BRASIL. Conselho Nacional de Educação. Resolução 01/2004. Instituiu Diretrizes Curriculares Nacionais para a Educação das Relações Étnico-Raciais e para o Ensino de História e Cultura Afro-Brasileira e Africana. 2014b. Disponível em: http//:portal.mec.gov.br/seesp/arquivos/pdf/res1.pdf. Acesso em: 20 fev. 2014.

BRASIL. Lei no 11.645 de 10 de março de 2008. Estabelece as diretrizes e bases da educação nacional, para incluir no currículo oficial da rede de ensino a obrigatoriedade da temática "História e Cultura Afro-Brasileira e Indígena". Diário Oficial da União. Brasília, 11/3/2008, p. 1. Disponível em: http://www.planalto.gov.br/ccivil_03/_ato2007-2010/2008/lei/l11645.htm. Acesso em: 10 fev. 2014.

BRASIL. Política Nacional de Assistência Social - PNAS. Brasília: Ministério do Desenvolvimento Social e Combate à Fome; Secretaria Nacional de Assistência Social, 2005. Disponível em: file://C:/Users/usuario/Downloads/Politica\%20Nacional\%20de\%20Assistencia\%20Social\%202013\%20PNAS\%202004\%20 e\%20Norma\%200peracional\%20Basica\%20de\%20Servico\%20Social\%202013\%20NOBSUAS\%20(1).pdf.

BRASIL. Orientações técnicas: Centro de Referência de Assistência Social - Cras. 1. ed. Brasília: Ministério do Desenvolvimento Social e Combate à Fome, 2009.

CASTRO, C. G. C. S. et al. "O ensino de história e cultura afro-brasileira e africana no Paraná". In: CONGRESSO NACIONAL DE EDUCAÇÃO - EDUCERE, 8., 2008, Curitiba. Anais [...]. Curitiba, 2008. p. 11.62811.642. Disponível em: http://www.pucpr.br/eventos/educere/educere2008/anais/pdf/1001_958.pdf. Acesso em: 25 fev. 2014.

DA MATTA, Roberto Augusto. O que faz o Brasil, Brasil? Rio de Janeiro: Rocco, 1986.

GIL, Antonio Carlos. Métodos e técnicas de pesquisa social. 2. ed. São Paulo: Atlas, 1989.

GUIMARÃES, Antonio Sérgio Alfredo. Preconceito racial: modos, temas e tempos. 2. ed. São Paulo: Cortez, 2012.

GOLDMANN, L. Dialética e cultura. 2. ed. Rio de Janeiro: Paz e Terra, 1979.

IMBITUVA. Memorial descritivo das equipes interdisciplinares. Imbituva/PR: Colégio Estadual Alcidez Munhoz - Ensino Fundamental e Médio. [201-?].

LIBÂNEO, José Carlos. Democratização da escola pública: a pedagogia crítico social dos conteúdos. 19. ed. São Paulo: Ed. Loyola, 2008.

LUIZ, Danuta Estrufika Cantoia. Emancipação e serviço social: a potencialidade da prática profissional. Ponta Grossa: Ed. UEPG, 2011. 
LUIZ, Danuta Estrufika Cantoia et al. "Programa de Saúde Mental em Palmeira - PR: perspectivas de um trabalho interdisciplinar." Relatório de Pesquisa do Núcleo de Estudos em Estado, Políticas Públicas e Práticas Sociais. Ponta Grossa: UEPG, 2014.

MARTINS, A. M. et al. Programa Municipal de Saúde Mental. Prefeitura Municipal de Palmeira, 1998. MARX, K. Introdução à crítica da economia política. In: MARX, K. Contribuição à crítica da economia política. 2. ed. São Paulo: Martins Fontes, 1983. p. 199-226.

MUNHOZ, Divanir. Eulália; OLIVEIRA JUNIOR, Constantino Ribeiro. "Interdisciplinaridade e pesquisa". In: BOURGUIGNON, J. A. Pesquisa social - reflexões teóricas e metodológicas. Ponta Grossa: Ed. Toda Palavra, 2009. p. 11-33.

PARANÁ. Conselho Estadual de Educação. Deliberação 04/2006. Delibera as Normas Complementares às Diretrizes Curriculares Nacionais para a Educação das Relações Étnico-Raciais e para o ensino de História e Cultura Afro-Brasileira e Africana. 2006a. Disponível em: http://www.educacao.pr.gov.br/arquivos/ File/.../deliberacao 042006.PDF.' Acesso em: 20 fev. 2014.

PARANÁ. Secretaria de Estado da Educação. Instrução no 017/2006. Instrui a educação das Relações Étnico-Raciais e o ensino de História e Cultura Afro-Brasileira e Africana, que passa a ser obrigatória em todos os níveis e modalidades dos estabelecimentos de ensino da rede pública estadual de Educação Básica. 2006b. Disponível em: http://www.nre.seed.pr.gov.br/pontagrossa/arquivos/File/.../Instrucao17. pdff. Acesso em: 21 fev. 2014.

PARANÁ. Secretaria de Estado da Educação. Instrução no 010/2010. Instrui equipes Multidisciplinares para tratar da Educação das Relações Étnico-Raciais e para o Ensino de História e Cultura Afro-brasileira, Africana e Indígena. 2010a. Disponível em: http://www.educacao.pr.gov.br/arquivos/File/instrucoes/instrucao102010.pdff. Acesso em: 21 fev. 2014.

PARANÁ. Secretaria de Estado da Educação. Resolução $n^{\circ}$ 3399/2010. Compor Equipes Multidisciplinares nos Núcleos Regionais de Educação - NREs - e Estabelecimentos de Ensino da Rede Estadual de Educação Básica. 2010b. Disponível em: http://www.nre.seed.pr.gov.br/pontagrossa/arquivos/File/.../Resolucao3399.pdf. Acesso em: 21 fev. 2014.

PARANÁ. Secretaria de Estado da Educação. Orientação 01/2012. Disponível em: http://www.nre.seed. pr.gov.br/pontagrossa/arquivos/.../orientacao_dedi.pdff. Acesso em: 21 fev. 2014.

RAMPAZZO, Lino. Metodologia científica para alunos dos cursos de Graduação e Pós-Graduação. São Paulo: Edições Loyola, 2005. Disponível em: books.google.com.br/books?id=rwyufjs_DhAC. Acesso em: 19 jun. 2013.

SIENA, Osmar. Metodologia da pesquisa científica: elementos para elaboração e apresentação de trabaIhos acadêmicos. Porto Velho: [s.n.], 2007. 200p. Disponível em: www.mestradoadm.unir.br/site_antigo/ doc/manualdetrabalhoacademicoatual.pdf. Acesso em: 18 jun. 2013.

SILVA, I. A. da; BARBOSA, P. "O ensino sobre história e cultura afro-brasileira e as limitações encontradas na implementação da Lei 10639/03." In: FILHO, G. R.; OLIVEIRA, C. C. de; NASCIMENTO, J. G. do (org.). Formação inicial, história e cultura africana e afro-brasileira: desafios e perspectivas na implementação da Lei federal 10.639/2003.1. Uberlândia, MG: Editora Gráfica Lops, 2012.

SOUZA, Cristiane Gonçalves de et al. "Práticas profissionais interdisciplinares nos Centros de Referência de Assistência Social (Cras) na Região dos Campos Gerai." Relatório de Pesquisa do Núcleo de Estudos em Estado, Políticas Públicas e Práticas Sociais. Ponta Grossa: UEPG, 2014.

THIESEN, J. "A interdisciplinaridade como um movimento articulador no processo ensino-aprendizagem". Rev. Bras. Educ. [on-line], vol. 13, n. 39, p. 545-554, 2008.

UEPG. Universidade Estadual de Ponta Grossa. "Dicionário histórico e geográfico dos Campos Gerais". Ponta Grossa, 2000. Disponível em: http://www.uepg.br/dicion/index.html. Acesso em: 12 out. 2013. YAZBEK, Carmelita. "As ambigüidades da Assistência Social brasileira após dez anos de LOAS". In: Revista Serviço Social e Sociedade, São Paulo: Cortez, ano XXV, n.77, 2004. p. 11-29. 